\title{
The Impact of Health Care Reform Initiatives on Ethical Conflict and Opportunities for Nurses to Improve Quality of Care While Enhancing Their Work Environments
}

\author{
Robert Cooper ${ }^{1}$, Garry Frank ${ }^{1}$, Cherry Shogren ${ }^{2}$ \\ ${ }^{1}$ College of Business and Public Administration, Drake University, Des Moines, USA \\ ${ }^{2}$ Professional Development, Unity Point Health-Des Moines, Des Moines, USA \\ Email: robert.cooper@drake.edu
}

Received 3 July 2014; revised 27 July 2014; accepted 5 August 2014

Copyright (C) 2014 by authors and Scientific Research Publishing Inc.

This work is licensed under the Creative Commons Attribution International License (CC BY). http://creativecommons.org/licenses/by/4.0/

c) (i) Open Access

\section{Abstract}

Background: After more than a decade of the nursing profession contending that healthcare reform based almost exclusively on cost cutting was creating an array of serious ethical issues for nurses, healthcare organizations and other providers are now facing increasing demands primarily from payers to demonstrate improvement in both quality of care and patient experience along with continued cost reduction. Research Question: Have efforts by healthcare organizations to comply with these recently imposed requirements influenced the ethical environment faced by nurses and nurse leaders and if so, how? Materials and Methods: Data for assessing the current ethical environment was gathered with a close-ended survey mailed in October 2012 to a random sample of $\mathbf{3 0 0 0}$ members of the American Organization of Nurse Executives. Results and Discussion: Statistical analysis of the data and comparison with the findings of a similar study conducted in $\mathbf{2 0 0 0}$ indicated that along with five highly rated issues in the earlier study attributed largely to economic constraints imposed by healthcare organizations, the top-10 key ethical issues today included five issues primarily attributable to interprofessional conflict. Conclusion: Given the success of many ongoing efforts aimed at weakening these key sources of ethical conflict that have blocked many proposals to improve the quality of care, opportunities should arise for the nursing profession to more fully achieve its goals of improving the quality of care, safety and patient satisfaction and enhancing nurses' work environments essential to that effort.

\section{Keywords}

Cost Control, End-of-Life Care, Ethical Consults, Futile Treatment, Healthcare Reform, Nursing Ethics, Patient Satisfaction, Quality of Care 


\section{Introduction}

Responding to significant pressures for increased cost control imposed on hospitals by managed care organizations through selective network contracting during the 1990s [1] [2], healthcare organizations (HCOs) subsequently undertook a number of reengineering and restructuring initiatives aimed at lowering the cost of delivering care [3]-[5]. Steps taken by HCOs included reduced staffing which led to increased patient loads, mandatory overtime, inadequate administrative support, overwhelming stress, less competitive wages, hazardous working conditions, and reduced support services for patient care [6]. Surveys of nurse leaders [7] and staff nurses [8] conducted in 2000 and 2002, respectively, to identify the key ethical issues those face in the profession indicated widespread disappointment in the eyes of consumers, nurses and other professionals with the quality of service provided by HCOs. Respondents to both studies attributed these outcomes primarily to economic constraints established by the organizations that led to conflict between organizational and clinical ethics. The outcome of this conflict saw numerous proposals by the nursing profession to improve the quality of care overwhelmed by the strength of HCOs' seemingly unconditional focus on cost control.

In recent years, governmental and nongovernmental payers have increasingly demanded that HCOs raise their standards for patient care, safety and satisfaction while continuing their efforts to reduce the cost of healthcare [9] [10]. For example, as Medicare's programs for reducing hospital readmissions [11] and increasing reliance on value-based purchasing [12] illustrate, failure to improve quality of care along with cost reduction is likely to have a negative impact on HCOs' reimbursements for services provided or opportunities to qualify for quality bonuses. In response, hospitals are taking steps to implement and assess the performance of a variety of initiatives aimed at improving quality of care, safety and patient satisfaction. In addition to development of effective interventions to reduce hospital readmissions and increase reliance on value-based purchasing, a wide array of innovative models are currently being designed and tested that would enable HCOs and providers to improve the quality of care while reducing costs by, among other things, preventing medical errors, providing better primary care, improving care coordination through team-based care and bundled care payment, providing holistic health care for people with chronic conditions, and focusing on cost-effective prevention, testing and treatment.

Under pressure from governmental and nongovernmental payers to broaden their organizational objectives beyond their traditional heavy emphasis on cost reduction to also include giving serious consideration to factors reflecting professional and personal values of critical importance to nurses, HCOs have created an opportunity and incentive for members of the nursing profession to fulfill their ethical responsibilities related to improving patient care, safety and satisfaction, as well as securing a suitable work environment essential to meet those obligations. In an effort to identify the key ethical issues nurses and their leaders face at this time as well as explore ethical environmental shifts over time, members of the American Organization of Nurse Executives (AONE) were recently surveyed. This paper presents the findings of the survey and compares them with those of the ethical issues survey of nurse executives conducted in 2000 [7]. The authors also discuss the implications for the profession and the healthcare industry today and in the future.

\section{Materials and Methods}

In October 2012, 3000 members of AONE were surveyed by mail. Survey participants were selected at random from AONE's membership list and each received a 3-page questionnaire. Prior to the start of the study, an exempt application for research (IRB 2011-12031) was submitted to the Institutional Review Board at Drake University and approved 20 March 2012 with no expiration date. Since those participating in the survey were promised anonymity, a follow-up letter was sent to each nurse leader surveyed thanking those who had responded and requesting input from those who had not.

The questionnaire was developed by modifying the form used in the issues survey of AONE members conducted by Cooper, Frank, Gouty and Hansen [7] in 2000. Survey modification was led by one of the authors and feedback regarding the revised form was sought from others in the local healthcare community as content experts.

The questionnaire presented 40 ethical issues listed in Table 1 . The nine lowest rated issues contained in the 2000 survey form were replaced with ethical problems receiving increased attention in the literature in recent years - that is, issues 14 - 22 in Table 1 . Survey participants were asked to rate each of the 40 issues on a 5point Likert scale ( $5=$ major problem; $1=$ not a problem) indicating the extent to which the issue presents an ethical problem to HCOs today. In an open-ended response, respondents were asked to indicate other ethical issues 
Table 1. Ethical issues in the 2012 study—all respondents $(\mathrm{N}=283)$.

\begin{tabular}{|c|c|c|c|}
\hline Issue & Mean* $^{*}$ & Rank & $\begin{array}{l}\text { Percent Indicating } \\
\quad 4 \text { or } 5\end{array}$ \\
\hline $\begin{array}{l}\text { 1. Failure to provide service of the highest quality in the eyes of the consumer regardless } \\
\text { of social or economic status, personal attributes or the nature of health problems }\end{array}$ & 2.73 & 8 & 29 \\
\hline $\begin{array}{l}\text { 2. Failure to provide service of the highest quality in the eyes of the health care providers } \\
\text { not employed by the organization }\end{array}$ & 2.48 & 16 & 21 \\
\hline $\begin{array}{l}\text { 3. Failure to provide service of the highest quality in the eyes of the purchasers of care } \\
\text { (e.g., insurance companies) }\end{array}$ & 2.71 & 10 & 29 \\
\hline $\begin{array}{l}\text { 4. Failure to provide service of the highest quality in the eyes of the health care providers } \\
\text { employed by the organization }\end{array}$ & 2.64 & 11 & 26 \\
\hline $\begin{array}{l}\text { 5. Failure to provide service of the highest quality consistent with the standards of the } \\
\text { nursing profession }\end{array}$ & 2.83 & 7 & 34 \\
\hline $\begin{array}{l}\text { 6. Failure to provide service of the highest quality due to economic constraints determined } \\
\text { by the organization }\end{array}$ & 3.32 & 2 & 52 \\
\hline 7. Failure to provide service of the highest quality consistent with the ANA Code of Ethics & 2.41 & 20 & 12 \\
\hline 8. Failure to provide honest information regarding resources, employee competence or service & 2.35 & 23 & 21 \\
\hline 9. Showing partiality toward clients perceived as influential & 2.58 & 12 & 25 \\
\hline 10. Showing partiality toward providers perceived as influential & 2.72 & 9 & 30 \\
\hline 11. Lack of knowledge or skills to competently perform one’s duties & 2.40 & 21 & 18 \\
\hline 12. Misrepresenting or concealing limitations in one's abilities to perform the assigned task & 2.15 & 30 & 12 \\
\hline $\begin{array}{l}\text { 13. Failure to identify the consumer's needs and provide services that meet those needs } \\
\text { (e.g., referrals) }\end{array}$ & 2.52 & 14 & 19 \\
\hline 14. Failure to provide quality end-of-life care & 3.13 & 4 & 44 \\
\hline 15. Failure to adequately assess the unique needs of the geriatric population & 3.19 & 3 & 44 \\
\hline $\begin{array}{l}\text { 16. Withholding or withdrawal of life-sustaining treatment against the patient's and/or } \\
\text { family's wishes or best interest }\end{array}$ & 2.13 & 31 & 16 \\
\hline 17. Failure to provide the patient and/or family full disclosure essential to informed consent & 2.42 & 18 & 22 \\
\hline 18. Failure of providers to discuss a patient's DNR status & 2.95 & 5 & 38 \\
\hline 19. Rationing of some forms of medical treatment due to scarcity of health care resources & 2.23 & 26 & 16 \\
\hline 20. Providing treatment when a positive outcome is highly unlikely & 3.38 & 1 & 53 \\
\hline 21. Providing misleading information to a patient regarding a diagnosis or prognosis & 2.35 & 23 & 18 \\
\hline 22. Failure by clinicians to use consults to address ethical issues regarding patient care & 2.89 & 6 & 35 \\
\hline 23. Failure to be objective with others in discharging one’s professional responsibilities & 2.51 & 15 & 18 \\
\hline $\begin{array}{l}\text { 24. Conflicts of interest involving consulting, marketing, business, or financial relationships } \\
\text { that influence, or appear to influence, one's ability to carry out his or her responsibility }\end{array}$ & 2.23 & 26 & 17 \\
\hline 25. Misuse of proprietary information & 1.78 & 39 & 8 \\
\hline 26. Misuse of sensitive information related to consumers and employees & 1.87 & 36 & 9 \\
\hline 27. Making disparaging remarks about competitors & 2.45 & 17 & 22 \\
\hline 28. Making disparaging remarks about vendors & 2.13 & 31 & 12 \\
\hline 29. Misuse of the organization's assets or property & 2.07 & 34 & 15 \\
\hline 30. Giving gifts or entertainment in an effort to influence decisions & 1.74 & 40 & 9 \\
\hline $\begin{array}{l}\text { 31. Offering or soliciting payments or contributions for the purpose of influencing legislation, } \\
\text { regulations or accreditation }\end{array}$ & 1.88 & 35 & 13 \\
\hline 32. Exaggerating the seriousness of a problem to obtain price or other concessions & 1.87 & 36 & 11 \\
\hline 33. Abuse of expense accounts & 1.81 & 38 & 10 \\
\hline 34. Department closings and layoffs & 2.55 & 13 & 27 \\
\hline 35. Discrimination in the work place & 2.23 & 26 & 16 \\
\hline 36. Drug and alcohol abuse in the workplace & 2.38 & 22 & 18 \\
\hline 37. Employee theft & 2.20 & 29 & 12 \\
\hline 38. Relationships with local communities & 2.10 & 33 & 12 \\
\hline 39. Relationships with other health care providers & 2.33 & 25 & 15 \\
\hline 40. Conflict between organizational and professional philosophy and standards & 2.42 & 18 & 21 \\
\hline
\end{tabular}

\footnotetext{
"Scale: 1 (not a problem)—5 (a major ethical problem).
} 
not listed in the survey form as well as to identify what they believe is the most important specific ethics problem or issue facing those who work as nurse leaders. Demographic information was also gathered anonymously about the respondent and the organization for which they worked.

In terms of organization level, approximately 44 percent of the respondents completing the survey indicated they were either vice presidents (35 respondents), chief nurse executives, CNEs (17) or chief nursing officers, CNOs (71), 31\% were directors (86), 12\% were managers (32), 2\% (5) were CEOs, 3\% (8) were COOs, and 9\% (25) indicated "other" - that is, other healthcare upper- or middle-management positions not identified in the survey.

With 39 surveys returned as undeliverable, responses were received from 283 of the 2961 AONE members successfully surveyed (9.6\%). While the response rate is too low to permit generalizations to be made regarding the views of all nurse leaders, the findings are grounded in a sufficient number of responses to provide a sense of the key ethical issues encountered in healthcare organizations today as compared with a decade ago, and serve as a resource for further research related to healthcare ethical issues and appropriate strategies for effectively dealing with them.

\section{Results}

Table 1 shows the mean ratings for each of the ethical issues based on the individual ratings given to that particular issue by survey respondents. The table also shows the rank of each issue based on the size of the issue's mean rating and the percentage of the respondents indicating 4 or 5 for the issue. For example, Issue 20 (providing treatment when a positive outcome is highly unlikely) was rated 3.38 on average by all respondents to the survey, had the highest mean rating among the 40 issues listed in the questionnaire, and was rated 4 or 5 by $53 \%$ of the respondents.

As indicated in Table 1, four issues (Issues 6, 14, 15 and 20) received mean ratings greater than 3.0, the midpoint on the rating scale, and were rated 4 or 5 by more than $43 \%$ of the nurse leaders responding to the survey. They were rated 5 , a major ethical problem today for health care organizations, by $17 \%$ or more of the respondents. Moreover, 6 more issues (Issues 1, 3, 5, 10, 18 and 22) have mean ratings above 2.70 and were rated 4 or 5 by $29 \%$ or more of those responding to the survey, suggesting that they are also perceived as presenting real problems for healthcare organizations.

\subsection{Five Key Ethical Issues Same as Those in 2000 Study}

As indicated later in the comparison of the findings of the two AONE issues studies, five of these top-rated issues were also highly ranked in the AONE 2000 issues study.

- Issue 1: Failure to provide service of the highest quality in the eyes of the consumer regardless of social or economic status, personal attributes or the nature of health problems (rank in $2012=8 ; 2000=4$ );

- Issue 3: Failure to provide service of the highest quality in the eyes of the purchasers of care, e.g., insurance companies (rank in $2012=10 ; 2000=12$ );

- Issue 5: Failure to provide service of the highest quality consistent with the standards of the nursing profession (rank in $2012=7 ; 2000=2$ );

- Issue 6: Failure to provide service of the highest quality due to economic constraints determined by the organization (rank in $2012=2 ; 2000=1$ ).

- Issue 10: Showing partiality toward providers perceived as influential (rank in $2012=9 ; 2000=9$ ).

In fact, the second highest rated issue in the current survey-Issue 6: failure to provide service of the highest quality due to economic constraints determined by the organization—ranked first in the earlier study. Issue 6 also ranked first among the responses to the open-ended 2012 survey question asking participants to indicate what they believe is the most important specific ethical problem facing those who work as nurse executives.

\subsection{Five New Key Ethical Issues}

As mentioned earlier, nine ethical issues were newly added to the 2012 survey form to replace the nine lowest ranked items in the 2000 study. The following five newly added issues were among those identified as presenting the top-six ethical problems for HCOs today:

- Issue 14: Failure to provide quality end-of-life care (rank 4); 
- Issue 15: Failure to adequately assess the unique needs of the geriatric population (rank 3);

- Issue 18: Failure of providers to discuss a patient's DNR status (rank 5);

- Issue 20: Providing treatment when a positive outcome is highly unlikely (rank 1);

- Issue 22: Failure by clinicians to use consults to address ethical issues regarding patient care (rank 6).

\subsection{Different Organizational Levels}

When the issue means were compared for the eight organizational level groups-CEOs, COOs, vice presidents, CNEs, CNOs, directors, managers and others - that responded to the survey, statistically significant differences were found for three key ethical issues. CEOs viewed Issue 14, failure to provide quality end-of-life care, as presenting significantly greater problems for HCOs than did COOs. Chief nurse executives, managers and those indicating "other" perceived Issue 18, failure of providers to discuss a patient's DNR status, as presenting significantly greater problems for HCOs than did CEOs, and managers also viewed Issue 20, providing treatment when a positive outcome is highly unlikely, as being a greater source of ethical problems than did CEOs.

As indicated in Table 2, correlation coefficients ranging from 0.733 to 0.954 suggest that the vice president, director, CNE, CNO, manager and the "other" groups when paired with one another have similar, and in five cases very similar, perceptions of the relative importance of the 40 issues. In contrast, in addition to no significant relationship being found between the CEO and COO group issue means, the low positive relationships between the CEO group and the other six organization level groups as well as with one exception (a high positive relationship between the $\mathrm{COO}$ and managers groups), the only moderately positive relationships found between the $\mathrm{COO}$ group and the other five groups give rise to a major concern.

\subsection{Comparison with the AONE 2000 Study's Findings}

As mentioned earlier, thirty-one of the 40 ethical issues included on the 2012 questionnaire were also on the 2000 issues survey form. This was done to permit a comparison of the findings of the two studies in an effort to examine the extent to which nurse leaders responding to the 2012 issues survey perceive the ethical environment in HCOs today as having changed, if at all, from that encountered more than a decade ago. Table 3 makes this comparison with the common issues listed in the order they ranked based on the relative size of their means in the 2012 study. Thus, for example, Issue 10, showing partiality toward providers perceived as influential, ranked 4th among the common issues included in the 2012 study with a mean rating of 2.72, but ranked 9th in the 2000 study based on its mean rating of 2.76 .

As indicated in Table 3, in many cases the common issue ranks in both studies were similar, in some cases identical. For example, Issue 6 (failure to provide service of the highest quality due to economic constraints determined by the organization) and Issue 5 (failure to provide service of the highest quality consistent with the standards of the nursing profession) ranked first and second, respectively, among the 31 issues common to both the 2000 and 2012 studies. In addition, respondents to both surveys perceived the following seven common issues as being among the 10 most problematic:

- Issue 1: Failure to provide service of the highest quality in the eyes of the consumer regardless of social or economic status, personal attributes or the nature of health problems (rank in $2012=3 ; 2000=4$ );

Table 2. Correlation coefficients for issue means of pairs of organizational level groups.

\begin{tabular}{clllllll}
\hline & CEO & COO & VP & Director & CNE & CNO & Manager \\
\hline COO & 0.262 & & & & & \\
VP & $0.405^{*}$ & $0.612^{*}$ & & & & \\
Director & $0.464^{*}$ & $0.679^{*}$ & $0.835^{*}$ & & & & \\
CNE & $0.456^{*}$ & $0.626^{*}$ & $0.733^{*}$ & $0.898^{*}$ & & & \\
CNO & $0.433^{*}$ & $0.671^{*}$ & $0.819^{*}$ & $0.954^{*}$ & $0.885^{*}$ & & \\
Manager & $0.467^{*}$ & $0.709^{*}$ & $0.806^{*}$ & $0.948^{*}$ & $0.848^{*}$ & $0.918^{*}$ & $0.941^{*}$ \\
Other & $0.421^{*}$ & $0.697^{*}$ & $0.818^{*}$ & $0.901^{*}$ & $0.749^{*}$ & $0.905^{*}$ \\
\hline
\end{tabular}

\footnotetext{
${ }^{*} \mathrm{p}<0.01$.
} 
Table 3. 2012 study and 2000 study common issues means and ranks—ordered by 2012 study ranks.

Issue

6. Failure to provide service of the highest quality due to economic constraints determined by the organization

5. Failure to provide service of the highest quality consistent with the standards of the nursing profession

1. Failure to provide service of the highest quality in the eyes of the consumer regardless of social or economic status, personal attributes or the nature of health problems

10. Showing partiality toward providers perceived as influential

3. Failure to provide service of the highest quality in the eyes of the purchasers of care (e.g., insurance companies)

4. Failure to provide service of the highest quality in the eyes of the health care providers employed by the organization

9. Showing partiality toward clients perceived as influential

34. Department closings and layoffs

13. Failure to identify the consumer's needs and provide services that meet those needs (e.g., referrals)

23. Failure to be objective with others in discharging one's professional responsibilities

2. Failure to provide service of the highest quality in the eyes of the health care providers not employed by the organization

27. Making disparaging remarks about competitors

40. Conflict between organizational and professional philosophy and standards

7. Failure to provide service of the highest quality consistent with the ANA Code of Ethics

11. Lack of knowledge or skills to competently perform one’s duties

36. Drug and alcohol abuse in the workplace

8. Failure to provide honest information regarding resources, employee competence or service

39. Relationships with other health care providers

24. Conflicts of interest involving consulting, marketing, business, or financial relationships

35. Discrimination in the work place

37. Employee theft

12. Misrepresenting or concealing limitations in one's abilities to perform the assigned task

28. Making disparaging remarks about vendors

38. Relationships with local communities

29. Misuse of the organization's assets or property

31. Offering or soliciting payments or contributions for the purpose of influencing legislation, regulations or accreditation

26. Misuse of sensitive information related to consumers and employees

32. Exaggerating the seriousness of a problem to obtain price or other concessions

33. Abuse of expense accounts

25. Misuse of proprietary information

30. Giving gifts or entertainment in an effort to influence decisions that influence, or appear to influence, one's ability to carry out his or her responsibility

2012 Study $N=2832000$ Study $N=334$

\begin{tabular}{|c|c|c|c|}
\hline Mean & Rank & Mean & Rank \\
\hline $3.32^{*}$ & 1 & 3.62 & 1 \\
\hline $2.83^{*}$ & 2 & 3.37 & 2 \\
\hline $2.73^{*}$ & 3 & 3.18 & 4 \\
\hline 2.72 & 4 & 2.76 & 9 \\
\hline 2.71 & 5 & 2.74 & 12 \\
\hline $2.64^{*}$ & 6 & 3.31 & 3 \\
\hline $2.58^{*}$ & 7 & 2.89 & 8 \\
\hline $2.55^{*}$ & 8 & 2.98 & 6 \\
\hline 2.52 & 9 & 2.55 & 16 \\
\hline 2.51 & 10 & 2.43 & 21 \\
\hline $2.48^{*}$ & 11 & 2.92 & 7 \\
\hline 2.45 & 12 & 2.34 & 25 \\
\hline $2.42^{*}$ & 13 & 3.00 & 5 \\
\hline $2.41^{*}$ & 14 & 2.76 & 9 \\
\hline $2.40^{*}$ & 15 & 2.60 & 14 \\
\hline $2.38^{*}$ & 16 & 2.69 & 13 \\
\hline 2.35 & 17 & 2.52 & 18 \\
\hline $2.33^{*}$ & 18 & 2.57 & 15 \\
\hline $2.23^{*}$ & 19 & 2.52 & 18 \\
\hline $2.23^{*}$ & 19 & 2.55 & 16 \\
\hline $2.20^{*}$ & 21 & 2.76 & 9 \\
\hline $2.15^{*}$ & 22 & 2.40 & 22 \\
\hline 2.13 & 23 & 2.11 & 30 \\
\hline $2.10^{*}$ & 24 & 2.44 & 20 \\
\hline 2.07 & 25 & 2.25 & 26 \\
\hline $1.88^{*}$ & 26 & 2.22 & 27 \\
\hline $1.87^{*}$ & 27 & 2.35 & 23 \\
\hline $1.87^{*}$ & 27 & 2.18 & 28 \\
\hline $1.81^{*}$ & 29 & 2.09 & 31 \\
\hline $1.78^{*}$ & 30 & 2.26 & 25 \\
\hline $1.74^{*}$ & 31 & 2.15 & 29 \\
\hline
\end{tabular}

${ }^{*} 2012$ study issue mean significantly lower than 2000 issue mean (at the 0.05 level). 
- Issue 4: Failure to provide service of the highest quality in the eyes of the health care providers employed by the organization (rank in $2012=6 ; 2000=3$ );

- Issue 5: Failure to provide service of the highest quality consistent with the standards of the nursing profession (rank in $2012=2 ; 2000=2$ );

- Issue 6: Failure to provide service of the highest quality due to economic constraints determined by the organization (rank in $2012=1 ; 2000=1$ );

- Issue 9: Showing partiality toward clients perceived as influential (rank in $2012=7 ; 2000=8$ );

- Issue 10: Showing partiality toward providers perceived as influential (rank in $2012=4 ; 2000=9$ );

- Issue 34: Department closings and layoffs (rank in $2012=8 ; 2000=6$ ).

A strong positive correlation coefficient for the means, 0.864 (significant at the 0.01 level), suggests that the order of the 31 issues common to both studies is quite similar overall.

The means for the common issues in the two studies were compared statistically in an effort to determine whether the ethical environment in HCOs was perceived by nurse leaders to have changed since the earlier survey conducted in 2000. As indicated in Table 3, statistically significant differences were found between the means for 23 of the 31 common issues. In all these cases, the AONE 2012 study mean was significantly lower than that for the AONE 2000 survey, suggesting nurse leaders perceive most of the common ethical issues to be presenting less of a problem today than they did more than a decade ago. In fact, with the exception of Issue 10, showing partiality toward providers perceived as influential, the top-ten ranked issues in the 2000 study received significantly lower ratings in the present study.

Six of the seven issues referring directly to failure to provide service of the highest quality that ranked in the top 10 in the earlier study were viewed as presenting less of a problem today, possibly a reflection of the success some HCOs have experienced with various healthcare delivery initiatives they established in recent years. Regardless, the quality of patient care and safety should improve considerably in the future in response to various incentive [penalty] programs established by the government and nongovernmental payers.

\section{Discussion}

\subsection{Key Ethical Issues Related to Organizational Cost Constraints}

While economic constraints are still perceived by nurse leaders responding to the 2012 survey as leading several groups, including, among others, consumers (patients and their families), providers and payers to continue to be dissatisfied with the quality of health care, the primary source of these constraints is changing as are expectations regarding their future impact on the value of care provided. Rather than arising from cost-cutting actions aimed primarily at maximizing the financial status of a particular organization, economic constraints imposed by HCOs in the future will more often be established in response to requirements imposed by governmental and nongovernmental payers in an effort to restrain the rapidly rising costs of the healthcare system. Moreover, accompanying these cost control requirements are demands from payers, consumers and regulators that HCOs and providers also improve outcomes, quality, safety and satisfaction in the future.

Ability to control costs and improve quality of care at the same time will, in turn, require increased innovation and cooperation by those working in HCOs. However, a growing body of research indicates that interventions can and are being developed successfully to accomplish both goals simultaneously [13]-[16]. While these efforts would continue to be challenging to the nursing profession, recent studies suggest that cooperation of nursing professionals and their organizations in efforts to improve quality of care, safety and patient satisfaction and enhance nurses' work environments may have very promising effects for patients, nurses and their organizations. Findings of a study including 27,509 nurses and 11,318 patients in the U.S. conducted by Aiken et al. [17] indicate, "Hospitals with good work environments and better professional nurse staffing have more satisfied patients and nurses, and evidence of better quality and safety of care." Findings of a study of readmission penalties received by 2826 hospitals conducted by McHugh, Berez and Small [18] indicate that those with higher nurse staffing had 25 percent lower odds of being penalized than those with lower staffing. The odds of receiving a maximum penalty were 41 percent lower with higher nurse staffing.

\subsection{Key Ethics Issues Related to Interprofessional Conflict and Inadequate Education and Training}

The top-ranked ethical problem identified by the respondents to the recent survey involves providing treatment 
when a positive outcome is highly unlikely (Issue 20)—-that is, futile treatment. The results of the 2012 Medscape survey of 24,000 physicians across 25 specialties indicated that only 24 percent of the participants responded "no" when asked if they would ever give life-sustaining therapy if they believed it to be futile [19]. With medical futility remaining controversial for physicians, it is understandable that in responding to the ethical principle of nonmaleficence, nurses encounter conflict not only with physicians, but also with patients, family members, other nurses and even themselves, often leading to either strong advocacy for patients' best interests or moral distress [20] [21]. According to Robichaux and Sauerland [22], "The virtues of moral courage, veracity, and compassion are essential in such situations". They [22] add, "To maintain a quality, ethical environment, management and leadership must support nurse advocacy and role model speaking up and create cultures that support acts of courage in nursing."

Caring for the elderly differs considerably from that for younger patients. As the human body changes with age so do the ways in which diseases present themselves and the body responds to various treatments. In addition, elderly patients often have multiple disorders often unknown to the physician that can complicate diagnosis and treatment [23]. Medication dosage levels for younger people are often not appropriate for older adults. Also, the elderly often take a larger number of prescription drugs that may cause a variety of problems. As a result, assessments as well as care planning, delivery and evaluation are more complex and subject to change in effectively dealing with geriatric patients. Research has indicated that care by nurses trained in geriatrics has benefitted older adults [24]. Unfortunately, however, according to Jennie Chin Hansen [25], CEO of the American Geriatrics Society, "There are not enough health providers, nurses included, who either specialize in geriatric care or who possess the necessary competency of geriatrics knowledge in their practice.” With limited attention given to geriatrics in nursing school at present, the burden for preparing nurses to effectively care for the elderly will fall primarily on training programs provided by HCOs and promoted by nurse leaders.

While conditions creating moral distress can be experienced throughout clinical practice, research indicates that the majority of situations are related to end of life care [26]. In addition to ethical issues related specifically to discussion of DNR status and futile treatment decisions, nurses also encounter an array of other situations associated with end-of-life care that also present serious ethical challenges and often lead to moral distress. Gruenewald [27] indicates that "patients near the end of life often receive aggressive yet unwanted medical interventions." Witnessing patient suffering has been found to present physicians and nurses alike with the greatest difficulty in connection with end of life care [28] [29]. Other factors contributing to ethical problems nurses encounter at end of life include lack of respect for them as well as patient autonomy, belief that the wrong course of medical treatment was chosen, inability to influence physicians, exclusion from participation in end of life decision making and formal end of life care conferences [30], failure to consider adoption of palliative care in an effort to improve the patient's quality of life [31], and poor communication throughout the process [21] [26]. LaSala and Bjarnason [32] conclude that action to effectively counter these and other causes of moral distress with moral courage is an obligation and responsibility of nurses in all roles across all settings. Nurses and nurse leaders alike must work together to promote moral courage in practice as well as with others in their HCO to build a work environment that supports ethical behavior. For example, in response to the common exclusion of nurses from end of life decision making and formal family conferences, Gutierrez [30] recommends that nurses should be encouraged, even expected, to participate in formal end of life care conferences with families and that nurse managers should work with medical directors to put in place a structure to ensure this occurs.

Research indicates that failure of providers to discuss a patient's DNR status remains a problem despite hospital-based initiatives to improve communication for more than a decade [33]. For a variety of reasons, patients' may have difficulty in gaining access to discussions with their physicians, and when they do, may find the sessions very short and lacking clearly presented information essential to making informed choices. Frequently, delay in DNR discussions with the patient leaves the decision in the hands of surrogates who may not be aware of what the patient wanted [34]. In addition to limited DNR discussions with patients, research also indicates nurses often are neither consulted in the decision process nor even allowed to initiate the DNR discussion [35]. In view of nurses' ethical obligation to "advocate for and play an active role in initiating discussions about DNR with patients, families and members of the health care team" [36], Lachman [37] argues "If physicians resist making time for these discussions, nurses must muster the moral courage to push for family meetings and, if unsuccessful, for ethics committee consults."

While 98 percent of the respondents to the AONE 2012 issues survey reported that their HCO has either a clinical ethics committee or both clinical and organizational ethics committees, the nurse leaders perceived fail- 
ure by clinicians to use consults to address ethical issues regarding patient care (Issue 22) to be among the topranked ethics-related problems faced by nurses. Research indicates that physicians and nurses alike have traditionally refrained from seeking an ethics consultation even in situations they find to be ethically difficult [38] [39]. Reasons physicians commonly choose not to use consults include, among other things, the belief they are not useful in solving ethical dilemmas [40], they intrude on the physician-patient relationship [40], they represent an abdication of the physician's responsibility to resolve issues with the patient or family, their timing is not consistent with the common physician goal of avoiding conflict in ethically difficult cases, they might lead the patient or family to doubt the physician's effectiveness in helping them with their decisions [41], they undermine the physician's role as the primary decision maker, and they might create legal problems. Reasons nurses avoid using ethical consultation include, among other things, fear of repercussions from asking questions or disagreeing with a plan of care [42], the organization's climate does not encourage ethical dialogue between nurses and other healthcare professionals but rather discourages it, the ethics committee has little power and thus, will not take a stand, nurses' requests for ethical consults may be viewed negatively leading to retaliation or alienation from physicians and other health team members, and "anonymous consultations may perpetuate and possibly escalate an adversarial environment without promoting collaboration or communication” [29]. Whereas the reasons given by physicians primarily reflect concerns that consultation might interfere with their responsibility for determining an appropriate course of action for a patient, nurses' reasons reflect primarily negative consequences they may encounter when carrying out their role of advocating for the patient's best interest. In responding to these repercussions that have been found in many cases to result in moral distress [28], Bosek [29] recommends that nurse managers should work to empower their nursing staff by, among other things, ensuring the organization's ethics consulting mechanism includes staff nurses' participation and viewpoints on ethical problems, encouraging nurses to improve their ethics knowledge through unit-based educational activities, providing a safe environment where nurses can discuss ethical concerns and potential responses with other providers and family members, and making themselves available to their nursing staff. Nurse leaders at higher levels should also work to ensure an organizational ethical climate that supports, even encourages, open discussion of ethical issues and possible solutions with other healthcare providers and members of patients' families. However, findings of differences in how nurse leaders holding senior management positions (CEOs and COOs) perceive the relative importance of the 40 issues as compared with respondents in the vice president, director, CNE, CNO, manager and the "other" groups, suggest a challenge may be encountered in efforts to define and implement an organizational culture that is built on truly commonly shared ethical values at all levels. It certainly suggests that effective communication between these top managers and those at other organization levels is critical to the success of such an effort.

While all of the key ethical issues identified involve the provision of less than acceptable quality care when measured against the professional obligations of nurse leaders, the main causes differ. For example, four of the top-10 ranked issues are unresolved do to a continuing clash between professional ethical values and organizational goals of cost containment, whereas the key ethics issues related to end-of-life care, geriatric care, DNR status, futile treatment and ethics consults are primarily attributable to interprofessional conflict, particularly between nurses and physicians, as well as inadequate educational preparation to deal effectively with challenges such as the changing special needs encountered in caring for the rapidly growing elderly population, and the increased reliance on collaboration and team-based care under initiatives responding to healthcare reform.

\section{Conclusions}

Despite the general decline in the extent to which the common ethical issues studied in 2000 were perceived by nurse leaders as presenting problems for HCOs today, the findings in Table 3 also emphasize the continued importance of ethical issues related to failure to provide quality care at the present time. Addition of the requirement for improved standards for patient care, safety and satisfaction to the existing goal of cost control has inserted an element into the goals of HCOs congruent with the professional values of nursing that should provide an opportunity for nurses and their leaders working in cooperation with others throughout the organization to improve the ethical environment encountered by healthcare professionals through enhancement of the quality of care provided, while, at the same time, contributing to the HCOs' competitiveness by enabling it to qualify for financial incentives as well as avoid penalties.

Efforts to deal effectively with the key ethical issues related to end-of-life care, geriatric care, DNR status, fu- 
tile treatment and ethics consults have also been challenging, because they reflect the traditional interprofessional conflict between the professional values of nursing and those of other healthcare professions, particularly physicians, as well as the lack of educational experiences providing members of the various professions with the knowledge of, and experience with, the critical skills and behaviors essential to effective collaboration and participation in team-based care. Recognizing the serious negative effects these factors can have on both the quality and cost of care, major efforts have been undertaken in recent years by the government, emerging policy and practice development organizations, and HCOs themselves to reduce the impact interprofessional conflict is having as a major barrier to the cost-effective delivery of healthcare.

Serious conflicts between professional values and organizational goals as well as those between the professional values of various healthcare providers have blocked the ability of the nursing profession to deal effectively with the key ethical issues it faces and thus, improve the quality of care to the extent desired. Ongoing efforts to reduce the negative influence of these conflicts should provide the nursing profession with an opportunity to better meet its goals of significantly improving the quality of care, safety and patient satisfaction and enhancing nurses' work environments.

\section{References}

[1] Shen, Y.-C. (2006) Is Managed Care Still an Effective Cost Containment Device? Forum for Health Economics \& Policy, 9, 1-24.

[2] Dranove, D., Lindrooth, R., White, W.D. and Zwanziger, J. (2008) Is the Impact of Managed Care on Hospital Prices Decreasing? Journal of Health Economics, 27, 362-376. http://dx.doi.org/10.1016/j.jhealeco.2007.05.004

[3] Ritter-Teitel, J. (2002) The Impact of Restructuring on Professional Nursing Practice. Journal of Nursing Administration, 32, 31-41. http://dx.doi.org/10.1097/00005110-200201000-00010

[4] Walston, S.L., Burns, L.R. and Kimberly, J.R. (2000) Does Reengineering Really Work? An Examination of the Context and Outcomes of Hospital Reengineering Initiatives. Health Services Research, 34, 1363-1388.

[5] Aiken, L.H., Clarke, S.P. and Sloane, D.M. (2000) Hospital Restructuring: Does It Adversely Affect Care and Outcomes? Journal of Nursing Administration, 30, 457-465. http://dx.doi.org/10.1097/00005110-200010000-00003

[6] Hussain, A., Rivers, P.A., Glover, S.H. and Fottler, M.D. (2012) Strategies for Dealing with Future Shortages in the Nursing Workforce: A Review. Health Services Management Research, 25, 41-47. http://dx.doi.org/10.1258/hsmr.2011.011015

[7] Cooper, R.W., Frank, G.L., Gouty, C.A. and Hansen, M.C. (2002) Key Ethical Issues Encountered in Healthcare Organizations: Perceptions of Nurse Executives. Journal of Nursing Administration, 32, 331-337. http://dx.doi.org/10.1097/00005110-200206000-00009

[8] Cooper, R.W., Frank, G.L., Hansen, M.M. and Gouty, C.A. (2004) Key Ethical Issues Encountered in Healthcare Organizations: The Perceptions of Staff Nurses and Nurse Leaders. Journal of Nursing Administration, 34, 149-156. http://dx.doi.org/10.1097/00005110-200403000-00008

[9] Gage, L. (2012) Transformational Governance: Best Practices for Public and Nonprofit Hospitals and Health Systems. Center for Healthcare Governance of the American Hospital Association. http://www.americangovernance.com/resources/reports/transformational-governance/

[10] Needleman, J. and Hassmiller, S. (2009) The Role of Nurses in Improving Hospital Quality and Efficiency: RealWorld Results. Health Affairs, 28, w625-w633. http://dx.doi.org/10.1377/hlthaff.28.4.w625

[11] Joynt, K.E. and Jha, A.K. (2013) A Path Forward on Medicare Readmissions. The New England Journal of Medicine, 368, 1175-1177. http://dx.doi.org/10.1056/NEJMp1300122

[12] Keckley, P., Coughlin, S. and Gupta, S. (2011) Value-Based Purchasing: A Strategic Overview for Health Care Industry Stakeholders. Deloitte Center for Health Solutions. http://www.deloitte.com/assets/Dcom-UnitedStates/Local\%20Assets/Documents/Health\%20Reform\%20Issues\%20Bri efs/US_CHS_ValueBasedPurchasing_031811.pdf

[13] Meeker, D., Knight, T.K., Friedberg, M.W., et al. (2014) Nudging Guideline-Concordant Antibiotic Prescribing: A Randomized Clinical Trial. JAMA Internal Medicine, 174, 425-431. http://dx.doi.org/10.1001/jamainternmed.2013.14191

[14] Community Preventive Services Task Force (2013) Annual Report to Congress. http://thecommunityguide.org/annualreport/2013-congress-report-full.pdf

[15] Grumbach, K. and Grundy, P. (2010) The Outcomes of Implementing Patient-Centered Medical Home Interventions: A Review of the Evidence from Prospective Evaluation Studies in The United States. Patient-Centered Primary Care 
Collaborative. http://www.cms.org/uploads/GrumbachGrundy2010OutcomesPCPCC.pdf

[16] Institute for Healthcare Improvement (2009) Effective Interventions to Reduce Hospitalizations: A Compendium of 15 Promising Interventions.

http://www.ihi.org/resources/Pages/Changes/EffectiveInterventionstoReduceRehospitalizationsCompendium15Promisi ngInterventions.aspx

[17] Aiken, L.H., Sermeus, W., Van den Heede, K., et al. (2012) Patient Safety, Satisfaction, and Quality of Hospital Care: Cross Sectional Surveys of Nurses and Patients in 12 Countries in Europe and the United States. British Medical Journal, 344, 1-14.

[18] McHugh, M.D., Berez, J. and Small, D.S. (2013) Hospitals with Higher Nurse Staffing Had Lower Odds of Readmission Penalties than Hospitals with Lower Staffing. Health Affairs, 32, 1740-1747.

http://dx.doi.org/10.1377/hlthaff.2013.0613

[19] Medscape (2012) Ethics Report: Physicians’ Top Ethical Dilemmas. http://www.medscape.com/features/slideshow/public/ethics2012

[20] Ferrell, B.R. (2006) Understanding the Moral Distress of Nurses Witnessing Medically Futile Care. Oncology Nursing Forum, 33, 922-930. http://dx.doi.org/10.1188/06.ONF.922-930

[21] Pavlish, C., Brown-Saltzman, K., Hersh, M., Shirk, M. and Nudelman, O. (2011) Early Indicators and Risk Factors for Ethical Issues in Clinical Practice. Journal of Nursing Scholarship, 43, 13-21. http://dx.doi.org/10.1111/j.1547-5069.2010.01380.x

[22] Robichaux, C. and Sauerland, J. (2012) Health Care Quality and Ethics: Implications for Practice and Leadership. Perioperative Nursing Clinics, 7, 333-342. http://dx.doi.org/10.1016/j.cpen.2012.06.002

[23] Merck (2013) Evaluation of the Elderly Patient. The Merck Manual for Health Care Professionals. http://www.merckmanuals.com/professional/geriatrics/approach_to_the_geriatric_patient/evaluation_of_the_elderly_p atient.html

[24] Kovner, C.T., Mezey, M. and Harrington, C. (2002) Who Cares for Older Adults? Workforce Implications of an Aging Society. Health Affairs, 21, 78-89. http://dx.doi.org/10.1377/hlthaff.21.5.78

[25] Robert Wood Johnson Foundation (2012) United States in Search of Nurses with Geriatrics Training. http://www.rwjf.org/content/rwjf/en/about-rwjf/newsroom/newsroom-content/2012/02/united-states-in-search-of-nurse s-with-geriatrics-training.html

[26] Wiegand, D.L. and Funk, M. (2012) Consequences of Clinical Situations That Cause Critical Care Nurses to Experience Moral Distress. Nurse Ethics, 19, 479-478. http://dx.doi.org/10.1177/0969733011429342

[27] Gruenewald, D.A. (2012) Can Health Care Rationing Ever Be Rational? Journal of Law, Medicine \& Ethics, 40, 17-25. http://dx.doi.org/10.1111/j.1748-720X.2012.00641.x

[28] Oberle, K. and Hughes, D. (2001) Doctors' and Nurses' Perceptions of Ethical Problems in End-of-Life Decisions. Journal of Advanced Nursing, 33, 707-715. http://dx.doi.org/10.1046/j.1365-2648.2001.01710.x

[29] Bosek, M. (2009) Identifying Ethical Issues from the Perspective of the Registered Nurse. JONA's Healthcare Law, Ethics, and Regulation, 11, 91-99. http://dx.doi.org/10.1097/NHL.0b013e3181b7a010

[30] Gutierrez, K.M. (2012) Prognostic Communication of Critical Care Nurses and Physicians at End of Life. Dimensions of Critical Care Nursing, 31, 170-182. http://dx.doi.org/10.1097/DCC.0b013e31824e0022

[31] Hodo, A. and Buller, L. (2012) Managing Care at the End of Life. Nursing Management, 43, 28-33. http://dx.doi.org/10.1097/01.NUMA.0000416400.63410.fa

[32] LaSala, C.A. and Bjarnason, D. (2010) Creating Workplace Environments That Support Moral Courage. The Online Journal of Issues in Nursing, 15, Manuscript 4.

http://www.nursingworld.org/MainMenuCategories/EthicsStandards/Courage-and-Distress/Workplace-Environments-a nd-Moral-Courage.html

[33] Anderson, W.G., Chase, R., Pantilat, S.Z., Tulsky, J.A. and Auerbach, A.D. (2011) Code Status Discussions between Attending Hospitalist Physicians and Medical Patients at Hospital Admission. Journal of General Internal Medicine, 26, 359-366. http://dx.doi.org/10.1007/s11606-010-1568-6

[34] Torke, A.M., Sachs, G.A., Helft, P.R., et al. (2011) Timing of Do-Not-Resuscitate Orders for Hospitalized Older Adults Who Require a Surrogate Decision-Maker. Journal of the American Geriatrics Society, 59, 1326-1331. http://dx.doi.org/10.1111/j.1532-5415.2011.03480.x

[35] Sulmasy, D.P., McAuley, R. and Ury, W.A. (2008) Beliefs and Attitudes of Nurses and Physicians about Do Not Resuscitate Orders and Who Should Speak to Patients and Families about Them. Critical Care Medicine, 36, 1817-1822. http://dx.doi.org/10.1097/CCM.0b013e31817c79fe

[36] American Nurses Association (ANA) (2012) Position Statement: Nursing Care and Do Not Resuscitate (DNR) and 
Allow Natural Death (AND) Decisions.

http://www.nursingworld.org/MainMenuCategories/EthicsStandards/Ethics-Position-Statements/Nursing-Care-and-Do -Not-Resuscitate-DNR-and-Allow-Natural-Death-Decisions.pdf

[37] Lachman, V. (2010) Do-Not-Resuscitate Orders: Nurse’s Role Requires Moral Courage. Medsurg Nursing, 19, $249-251$.

[38] Romano, M.E., Wahlander, S.B., Lang, B.H., Li, G. and Prager, K.M. (2009) Mandatory Ethics Consulting Policy. Mayo Clinic Proceedings, 84, 581-585. http://dx.doi.org/10.1016/S0025-6196(11)60746-5

[39] Fox, E., Myers, S. and Pearlman, R.A. (2007) Ethics Consultation in United States Hospitals: A National Survey. The American Journal of Bioethics, 7, 13-25. http://dx.doi.org/10.1080/15265160601109085

[40] Hurst, S.A., Hull, S.C., DuVal, G. and Danis, M. (2005) How Physicians Face Ethical Difficulties: A Qualitative Analysis. Journal of Medical Ethics, 31, 7-14. http://dx.doi.org/10.1136/jme.2003.005835

[41] Orlowski, J.P., Hein, S., Christensen, J.A., Meinke, R. and Sincich, T. (2006) Why Doctors Use or Do Not Use Ethics Consultation. Journal of Medical Ethics, 32, 499-503. http://dx.doi.org/10.1136/jme.2005.014464

[42] Otto, S. (2007) Request an Ethics Consult to Resolve Dilemmas. Nursing 2007 Critical Care, 2, 18-20. 
Scientific Research Publishing (SCIRP) is one of the largest Open Access journal publishers. It is currently publishing more than 200 open access, online, peer-reviewed journals covering a wide range of academic disciplines. SCIRP serves the worldwide academic communities and contributes to the progress and application of science with its publication.

Other selected journals from SCIRP are listed as below. Submit your manuscript to us via either submit@scirp.org or Online Submission Portal.
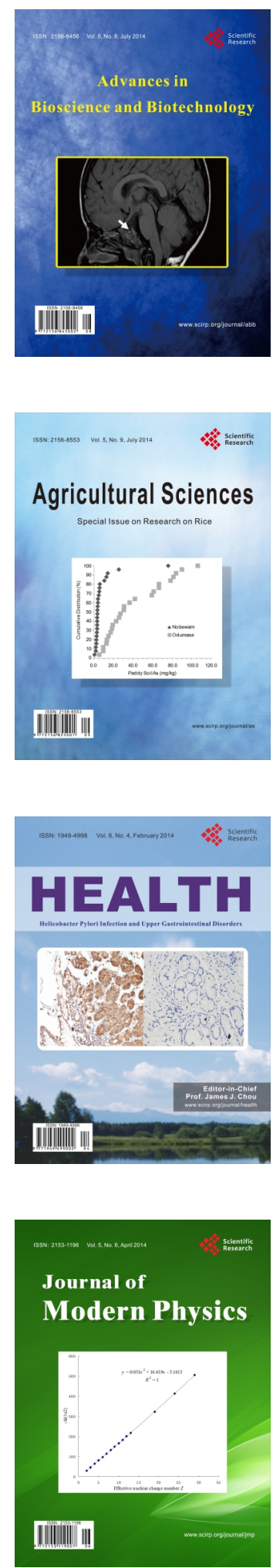
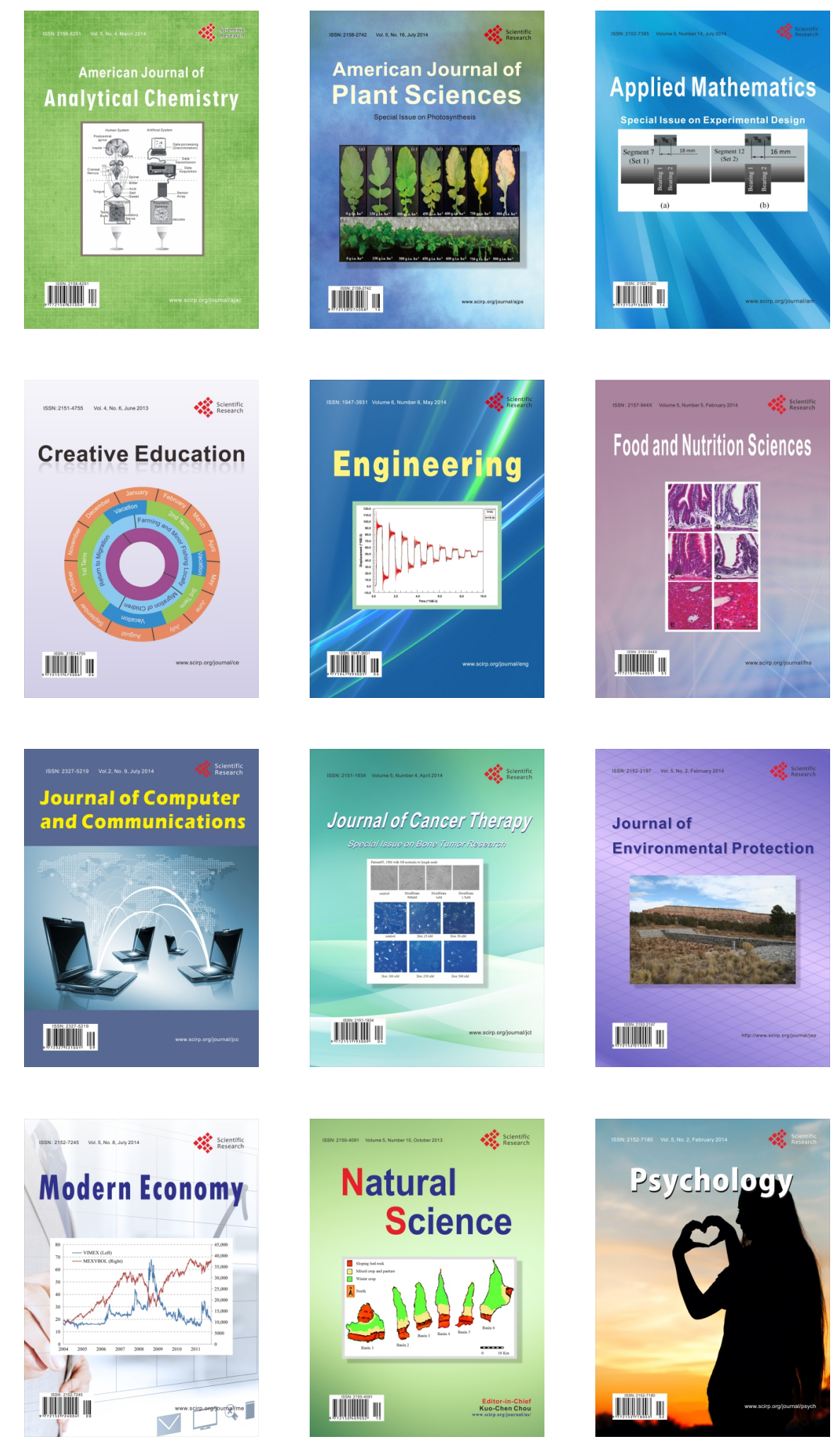